\title{
Body of Stomach
}

National Cancer Institute

\section{Source}

National Cancer Institute. Body of Stomach. NCI Thesaurus. Code C12258.

The main section of the digestive tube that connects the esophagus to the small intestine. The body proper excludes the upper and lower sections of the fundus and pyloric portion respectively. 